\title{
INFLUÊNCIA DA ARQUITETURA FOLIAR DE MINIESTACAS NA PROPAGAÇÃO CLONAL DE Eucalyptus ${ }^{1}$
}

Alan Ferreira Batista², Glêison Augusto dos Santos³ ${ }^{3}$ Luciana Duque Silva ${ }^{4}$, Franco Freitas Quevedo ${ }^{5}$ e Teotônio Francisco de Assis ${ }^{6}$

\begin{abstract}
RESUMO - Apesar do progresso da silvicultura clonal alcançado por meio da técnica de miniestaquia, pouco se avançou em relação às espécies recalcitrantes, sobretudo com relação ao manejo empregado em miniestacas. Com o objetivo de avaliar a influência da arquitetura de miniestacas na produção de mudas de quatro clones de Eucalyptus, foram realizadas avaliações nas três fases de produção de mudas: 1) Sobrevivência aos 30 dias em casa de vegetação, 2) Enraizamento aos 45 dias em casa de sombra; e 3) Aproveitamento final aos 60 dias na área de rustificação. A taxa de enraizamento foi determinada com base na taxa de sobrevivência aos 30 dias. O delineamento experimental utilizado foi em blocos casualizados com arranjo de tratamento em esquema fatorial $3 \times 4$, sendo três tipos de arquitetura de miniestaca: 1) folha inteira (100\%); 2) folha cortada (50\%); e 3) miniestaca cortada em "árvore de natal" (folhas subapicais cortadas em $3 / 4$ e basais inteiras) e quatro clones de (Eucalyptus E. dunnii, E. saligna e dois de E. urophylla x E. globulus), com quatro repetições e 100 plantas por bloco. De acordo com os resultados, a produção de mudas foi afetada pelo tipo de arquitetura de miniestacas. A arquitetura que apresentou os melhores resultados nas avaliações foi "árvore de natal" e folha inteira.
\end{abstract}

Palavras-chave: Viveiro; Clonagem; Enraizamento.

\section{INFLUENCE OF LEAF ARCHITECTURE OF MINICUTTINGS IN CLONAL PROPAGATION OF Eucalyptus}

\begin{abstract}
Despite the advances on minicutting techniques for clonal silviculture, little progress has been made considering recalcitrant species, especially for the handling in minicuttings practices. The objective was to evaluate the influence of the architecture of minicuttings in the production of four clones of Eucalyptus seedlings. Evaluations in the three phases of seedlings production were performed: 1) Survival at 30 days in the greenhouse; 2) Rooting at 45 days in the shade house; and 3) Final exploitation at 60 days in the rustication area. The rooting rates was calculated based on the surviving rates at 30 days. The experimental design was randomized blocks with treatment in a factorial scheme $3 \times 4$, with three types of minicutting architecture: 1) whole leaf (100\%); 2) cut leaf (50\%); and 3) minicutting in the form of a "christmas tree" (sub apical leaves cut in $3 / 4$ and basal leaves left uncut) and four clones of Eucalyptus (E. dunnii, E. saligna), and two clones of $\boldsymbol{E}$. urophylla $x$ E. globulus. We used 100 plants per block with four replications. The results have shown that the production of seedlings was affected by the type of architecture adopted in the minicuttings. The architecture that showed the best results in the evaluations were "christmas tree" and whole leaf.
\end{abstract}

Keywords: Nursery; Cloning; Rooting.

\footnotetext{
${ }^{1}$ Recebido em 29.05.2012 aceito para publicação em 04.07.2014.

${ }^{2}$ Assuntos Florestais, Indústria Brasileira de Árvores , IBA, Brasil. E-mail: <alan.batista@iba.org>. E-mail: <alan.batista@usp.br>.

${ }^{3}$ Centro de Produção Tecnológica, CMPC Celulose Riograndense, Brasil. E-mail: <gaugusto@cmpcrs.com.br>.

${ }^{4}$ Escola Superior de Agricultura "Luiz de Queiroz" - ESALQ/USP, Universidade de São Paulo, Brasil. E-mail: <lucianaduques@usp.br> .

${ }^{5}$ Centro de Produção Tecnológica, CMPC Celulose Riograndense, Brasil. E-mail: <ffquevedo@cmpcrs.com.br>.

${ }^{6}$ Assistech Serviços Técnicos Florestais Ltda., Brasil. E-mail: <assisteo@terra.com.br>.
} 


\section{INTRODUÇÃO}

Embora a clonagem pela técnica de estaquia tenha revolucionado a cultura do eucalipto no Brasil, esta técnica apresentava baixos percentuais de enraizamento e perdas na manutenção desses índices. No fim da década de 1990, foi implementada a propagação vegetativa por miniestaquia (WENDLING et al., 2000), que elevou consideravelmente os índices de enraizamento de diferentes espécies e clones, principalmente dos recalcitrantes à propagação vegetativa. A clonagem via miniestaquia possibilitou a maximização dos plantios clonais no Brasil, em escala comercial. Essa técnica ampliou um dos "negócios florestais”, que foi o surgimento de diversos viveiros independentes (não ligados às empresas florestais), que começaram a disponibilizar no mercado milhões de mudas clonais de Eucalyptus por ano.

Embora a técnica de miniestaquia possa dispensar o uso de reguladores de crescimento (ASSIS, 2001), vários autores utilizaram como promotor de enraizamento de miniestacas o ácido indolbutírico, obtendo diferentes repostas (WENDLING; XAVIER, 2005; ALMEIDA, 2006; GOULART, 2007; BRONDANI, 2008; BORGES et al., 2011). Hoje, os hormônios promotores de enraizamento são pouco utilizados em produção de mudas de Eucalyptus por miniestaquia em escala comercial (XAVIER; DA SILVA, 2010; ASSIS; MAFIA, 2007).

A hibridação com espécies tropicais, principalmente E. urophylla, é uma técnica que visa melhorar a adaptação dessas espécies às condições ambientais e também facilita a propagação vegetativa de espécies recalcitrantes ao enraizamento (ASSIS; MAFIA, 2007).

Há uma tendência em buscar diferentes padrões na confecção de miniestacas, principalmente a área foliar, com o propósito de promover a propagação vegetativa de espécies consideradas recalcitrantes ao enraizamento (SANTANA et al., 2010; SOUZA et al., 2013). Existe relação positiva entre área foliar de miniestacas e potencial de enraizamento destas. A concepção de confecção de miniestacas, hoje, privilegia na sua arquitetura final as folhas apicais e subapicais (drenos) em detrimento das folhas basais (fontes), que na miniestaca são fotossinteticamente mais ativas (ALFENAS et al., 2009), uma vez que as folhas apicais e subapicais ainda não estão totalmente formadas e prontas para o processo fotossintético.
A perda de água é uma das principais causas de perdas nos índices de enraizamento e morte de miniestacas. Para ocorrer a divisão celular, é necessário que as células do tecido estejam túrgidas (NORBERTO et al., 2001). A fim de evitar a perda de água por transpiração, Alfenas et al. (2004) propuseram a redução da lâmina foliar de miniestacas. Em adição, Xavier et al. (2009) citaram que a redução de 50\% da área foliar das miniestacas é a proporção mais comum na produção clonal de mudas de eucalipto no Brasil.

Diante do exposto, este estudo teve como objetivo avaliar a influência da arquitetura de miniestacas na produção de mudas clonais de Eucalyptus recalcitrantes.

\section{MATERIAL E MÉTODOS}

\section{1. Área de estudo}

Este estudo foi realizado no viveiro de mudas da empresa CMPC Celulose Riograndense, localizado no Município de Barra do Ribeiro, RS, no Horto Florestal Barba Negra, na latitude de $30^{\circ} 17^{\prime \prime}$ Sul, longitude 51 - 18" Oeste e altitude de $12 \mathrm{~m}$. De acordo com a classificação de Köppen, o clima predominante na região é do tipo Cfa, subtropical úmido, e a precipitação média anual é de aproximadamente $1.400 \mathrm{~mm}$. A temperatura da média do mês mais quente não ultrapassa $25^{\circ} \mathrm{C}$ e a do mês mais frio, $14^{\circ} \mathrm{C}$, com ocorrência de geadas leves.

\subsection{Manejo de minijardim clonal}

As minicepas de onde foram coletadas as miniestacas utilizadas na realização do estudo foram plantadas em leitos de areia fertirrigadas em sistema de gotejamento automatizado, sob abrigo de teto retrátil. O sistema de fertirrigação foi acionado de três a quatro vezes ao dia, dependendo das condições climáticas, despejando $5 \mathrm{~L} \mathrm{~m}^{-2}$ por dia de solução e condutividade elétrica (Ec) mantida em 1,8 mS m². A solução nutritiva foi composta por nitrato de cálcio $\left(367,5 \mathrm{mg} \mathrm{L}^{-1}\right)$; fosfato de monoamônio $\left(60,2 \mathrm{mg} \mathrm{L}^{-1}\right)$; cloreto de potássio (239,4 $\left.\mathrm{mg} \mathrm{L}^{-1}\right)$; sulfato de magnésio (113,6 $\left.\mathrm{mg} \mathrm{L}^{-1}\right)$; quelato de ferro (5,0 $\left.\mathrm{mg} \mathrm{L}^{-1}\right)$; boro orgânico $\left(0,5 \mathrm{mg} \mathrm{L}^{-1}\right)$; sulfato de manganês $\left(1,8 \mathrm{mg} \mathrm{L}^{-1}\right)$; sulfato de cobre $\left(0,15 \mathrm{mg} \mathrm{L}^{-1}\right)$; e sulfato de zinco $\left(0,25 \mathrm{mg} \mathrm{L}^{-1}\right)$. O intervalo entre a coleta e o plantio das miniestacas foi de 20 min até que elas fossem levadas para a casa de vegetação, após terem sido plantadas em tubetes de polipropileno com volume de $55 \mathrm{~cm}^{3}$, em substrato composto por 
20\% de vermiculita e $80 \%$ de turfa canadense e adubação de base (PG mix ${ }^{\mathrm{TM}}$; Super simples (fosfato) e Osmocote (NPK; 19:06:10), respectivamente nas dosagens de 2,0 kg; 2,0 kg; e 1,5 $\mathrm{kg} \mathrm{m}^{-3}$ de substrato). O plantio das miniestacas foi realizado na área designada para essa atividade, denominado galpão de estaqueamento. Cada bloco do experimento (bandeja com 100 mudas estaqueadas cada) foi realizado em intervalos de $5 \mathrm{~min}$, por dois colaboradores florestais simultaneamente, e em seguida as bandejas com mudas foram conduzidas para as casas de vegetação. Essas casas possuem sistema de irrigação por nebulização realizada por bicos do tipo fogger com vazão de $7,5 \mathrm{~L} \mathrm{~h}^{-1}$, com controle automatizado de umidade e lâmina de água, variando a intensidade de acordo com as condições climáticas. Na fase de rustificação, o sistema de irrigação é do tipo por aspersão com vazão de $120 \mathrm{~L} \mathrm{~h}^{-1}$, e, assim como em todas as outras etapas de irrigação, a intensidade varia de acordo com as condições climáticas.

\subsection{Experimento}

O experimento foi instalado no mês de abril de 2011 e avaliado por um período de dois meses. O delineamento experimental foi em blocos casualizados em esquema fatorial $3 \times 4$, sendo três arquiteturas de miniestacas e quatro clones diferentes de Eucalyptus (Tabela 1). O experimento foi composto por quatro repetições de 100 plantas por parcela, dispostas no centro da bandeja, que possui capacidade para 228 plantas.

As arquiteturas das miniestacas se dividem em três (Figura 1): A1 - miniestacas produzidas de folhas inteiras e intactas; A2 - miniestacas com todas as folhas cortadas, limbo foliar reduzido em 50\%; A3 - miniestacas do tipo “árvore de natal”, onde foram seccionados $75 \%$ do limbo foliar das folhas apicais e subapicais, deixando as folhas basais inteiras e intactas. O nome do tratamento A3 foi designado "árvore de natal” pela semelhança da silhueta da miniestaca a uma conífera.
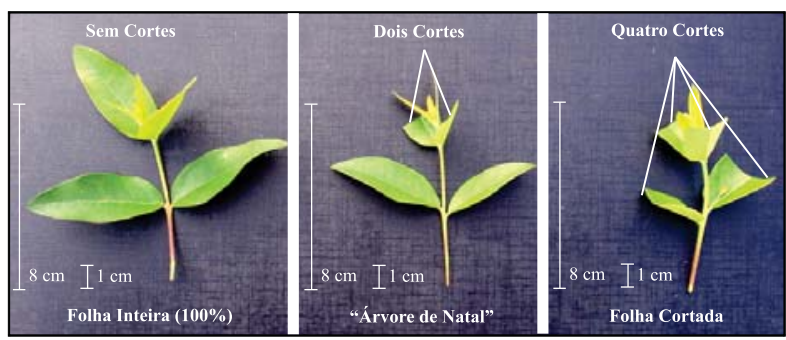

Figura 1 - Arquitetura das miniestacas utilizadas no teste: folha inteira (100\%), “Árvore de Natal” e folha cortada (50\%). Figure 1 - Minicutting architecture used in the test: whole leaf (100\%), “christmas tree” and cut leaf (50\%).

\subsection{Coleta de dados}

As avaliações foram realizadas em três fases da produção de mudas: 1) sobrevivência aos 30 dias em casa de vegetação; 2) enraizamento aos 45 dias em casa de sombra; e 3) aproveitamento final aos 60 dias na área de rustificação. A metodologia das avaliações foi semelhante às usadas por outros autores, como Schwanbach et al. (2008).

\subsubsection{Sobrevivência aos 30 dias em casa de vegetação}

Para avaliação de sobrevivência, realizada aos 30 dias, dentro da casa de vegetação, foi quantificado o número de plantas vivas, e a taxa de sobrevivência é dada pela equação 1 .

$$
\mathrm{S} \%=(\mathrm{V} / \mathrm{P}) * 100
$$

$\mathrm{S} \%$ = taxa de sobrevivência, em porcentagem;

$\mathrm{V}=\mathrm{n}^{\circ}$ de plantas vivas; $\mathrm{e}$

$\mathrm{P}=\mathrm{n}^{\circ}$ de plantas estaqueadas no experimento.

\subsubsection{Enraizamento aos 45 dias em casa de sombra}

A avaliação de enraizamento foi determinada na etapa de casa de sombra aos 45 dias de idade, em porcentagem (equação 2), onde foi avaliado o número de plantas enraizadas em função do número de plantas

Tabela 1 - Descrição dos tratamentos.

Table 1 - Treatments description.

\begin{tabular}{lccc}
\hline Clone & Material Genético & Arquitetura 1 & Arquitetura 2 \\
\hline 32864 & E. saligna & Folha inteira (100\%) & Folha cortada (50\%) \\
37423 & $\begin{array}{l}\text { E. urophylla } x \\
\text { Elobulus globulus } \\
\text { E. urophylla } x\end{array}$ & Folha inteira (100\%) & Folha cortada (50\%) \\
37254 & $\begin{array}{c}\text { E. globulus maideni } \\
\text { E. dunnii }\end{array}$ & Folha inteira (100\%) & Folha cortada (50\%) \\
D1005 & Folha inteira (100\%) & Folha cortada (50\%) \\
\hline
\end{tabular}


vivas contabilizadas na etapa de sobrevivência. As avaliações da emissão das raízes foram feitas de forma visual na extremidade do tubete, sem desagregar o substrato.

$$
\begin{aligned}
& \mathrm{E} \%=(\mathrm{e} / \mathrm{S}) * 100 \\
& \mathrm{E} \%=\text { taxa de enraizamento em porcentagem; } \\
& \mathrm{e}=\mathrm{n}^{\circ} \text { de plantas com raiz aos } 45 \text { dias; e } \\
& \mathrm{S}=\mathrm{n}^{\circ} \text { de plantas vivas na saída da casa de vegetação. }
\end{aligned}
$$

\subsubsection{Aproveitamento final aos 60 dias na área de rustificação}

Para avaliação de aproveitamento final de mudas no experimento, foi realizada uma seleção das mudas aos 60 dias de idade, quando foram descartadas as mudas mortas ou que não emitiram raiz, abrindo-se o espaçamento da bandeja, ficando com uma densidade de 60 plantas por bandeja ou espaçamento aproximado de $25 \%$ da área da bandeja (bandeja de 228 células). Essa avaliação foi realizada na fase de rustificação, e a taxa de aproveitamento final foi determinada pela equação 3 .

$$
\mathrm{AF} \%=(\mathrm{P} / \mathrm{D}) * 100
$$

$\mathrm{AF} \%$ = taxa de aproveitamento final, em porcentagem;

$\mathrm{P}=\mathrm{n}^{\circ}$ de plantas vivas aos 60 dias de idade; e

$\mathrm{D}=\mathrm{n}^{\circ}$ de plantas estaqueadas no experimento.

\subsection{Análise de dados}

Os pressupostos de normalidade dos erros e homogeneidade da variância entre os tratamentos foram verificados pelos testes de Hartley e Lilliefors, respectivamente, fixando-se o nível de significância em $5 \%$.

Após a verificação da homogeneidade das variâncias, optou-se pela transformação angular dos dados (equação 4 - com base em BANZATTO, 1989).

$$
y t=\operatorname{arcosseno} \sqrt{ }(y \div 100)
$$

em que:

yt = variável transformada; e

y = variável obtida nas avaliações.

Os dados foram submetidos à análise de variância (ANOVA) a 5\% de significância $(p<0,05)$. As médias foram comparadas pelo teste de Tukey, fixando-o com o mesmo nível de significância.

\section{RESULTADOS}

Com base nos resultados da análise de variância, verificou-se que diferentes arquiteturas de miniestacas possuem interação com clones no ciclo de produção de mudas.

Conforme apresentado na Figura 2, não houve diferença significativa da variável sobrevivência dos clones D.1005 (E. dunnii) e 32864 (E. saligna) a 5\% de significância. Para o híbrido 37254, a sobrevivência foi maior nas arquiteturas de miniestacas com folha cortada e "árvore de natal”, enquanto no híbrido 37423 a arquitetura de miniestaca "árvore de natal” foi significativamente superior. A sobrevivência no enraizamento de miniestacas é fator de grande importância e pode ser indicador fundamental para os ajustes de manejo em casa de vegetação.

$\mathrm{Na}$ avaliação de enraizamento, optou-se por computar o número de miniestacas enraizadas em relação às miniestacas vivas. Esse conceito baseia-se na observação de que miniestacas mortas não enraízam e, na maioria das vezes, os fatores que levam a miniestaca à morte não estão ligados à sua habilidade de enraizamento. Um sistema de casa de vegetação bem manejado e equilibrado com as exigências de cada material genético deve manter 100\% das miniestacas vivas, dando oportunidade para que todas elas possam emitir raízes. As taxas de enraizamento (Figura 3) indicaram que nos clones 37423, 37254 e 32864 a arquitetura de miniestaca "árvore de natal” foi superior e, ainda, no clone 37423 essa arquitetura de miniestaca com folha inteira também foi superior em relação à arquitetura folha cortada. No clone D. 1005 não houve diferenças significativas entre os tratamentos.

O experimento envolveu a análise de mudanças no padrão de confecção de miniestacas. Mudanças na arquitetura das miniestacas alteraram significativamente as taxas de aproveitamento final (Figura 4) e apontaram que a arquitetura de miniestacas em “árvore de natal” foi significativamente superior às demais arquiteturas testadas nos clones 32864 e 37423. Em relação ao clone 37254, não houve diferenças significativas entre as arquiteturas de miniestacas folha cortada ou “árvore de natal”. No clone D. 1005, não houve diferenças significativas em nenhuma das arquiteturas de miniestaca. 


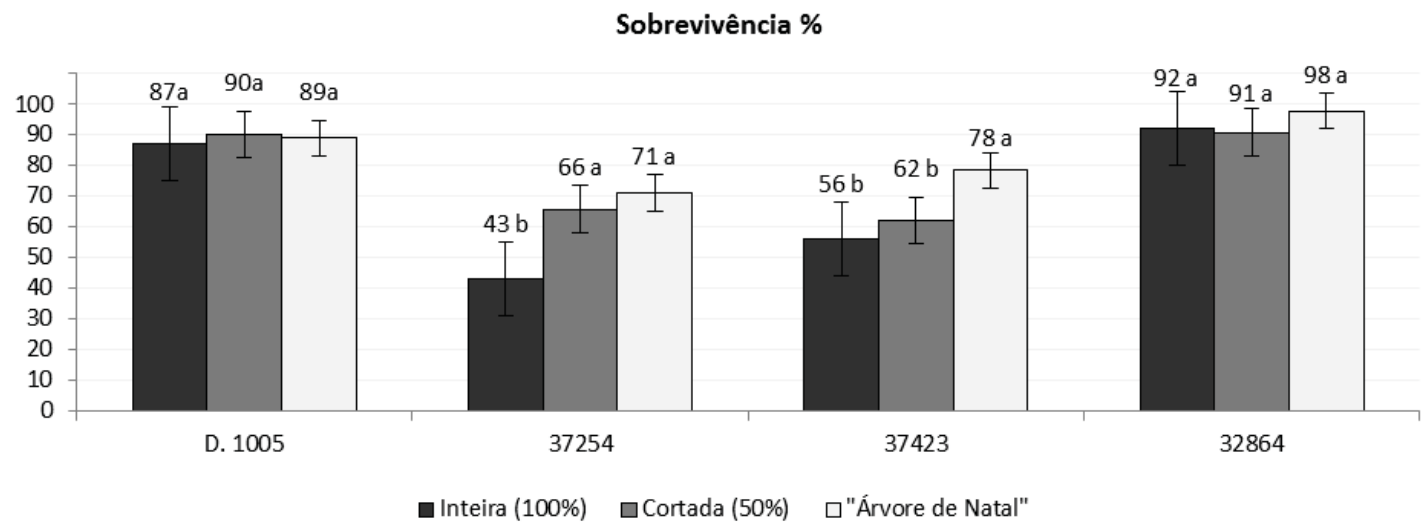

Figura 2 - Índices de sobrevivência de miniestacas expressos em porcentagem, aos 30 dias de idade, na saída da casa de vegetação. Letras diferentes indicam médias significativamente diferentes a de $5 \%$.

Figure 2 - Survival rates of minicuttings in percentage, at 30 days in the end of the period in the greenhouse. Different letters mean significantly different averages at $5 \%$.

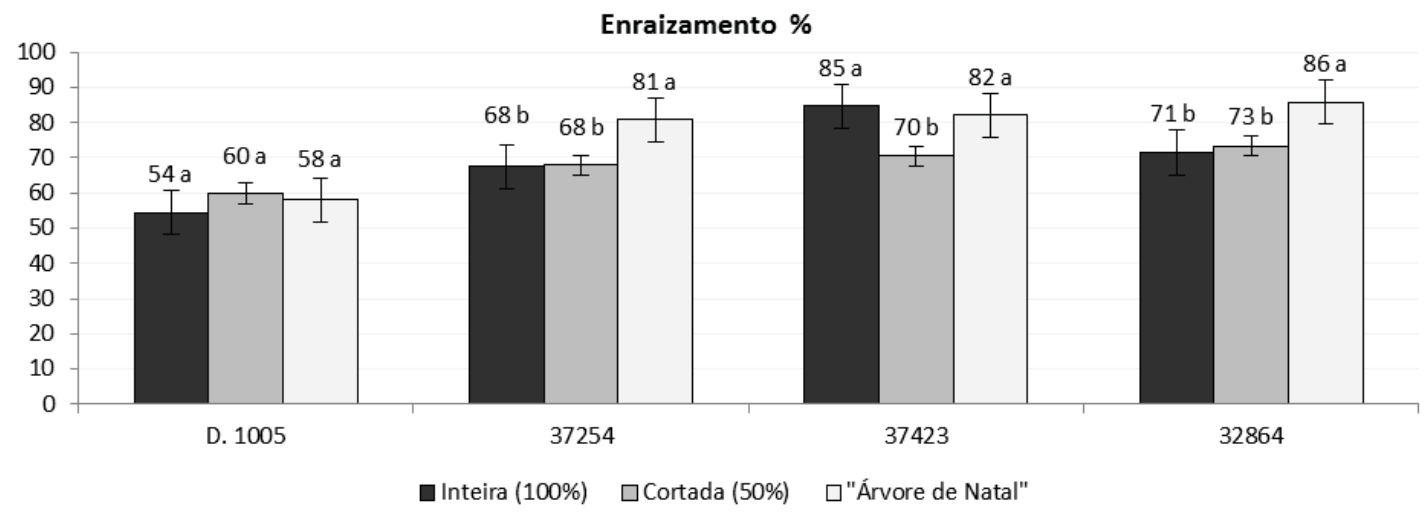

Figura 3 - Taxas de enraizamento de miniestacas expressas em porcentagem, aos 45 dias de idade, na saída na casa de sombra. Letras diferentes significam médias significativamente diferentes a 5\%.

Figure 3 - Rooting rates of minicuttings in percentage, at 45 days in the end of the period in the shade house. Different letters mean significantly different averages at $5 \%$.

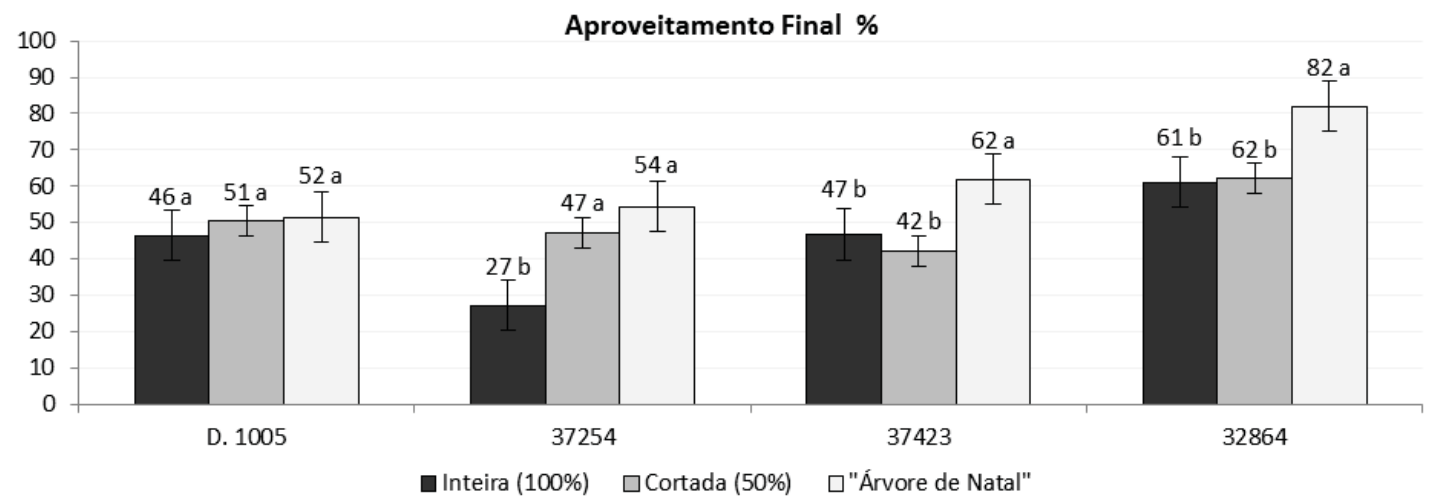

Figura 4 - Taxa de aproveitamento final de miniestacas expressa em porcentagem, aos 60 dias de idade, na fase de rustificação. Letras diferentes significam médias significativamente diferentes a 5\%.

Figure 4 -Rates of final exploitation of minicuttings in percentage, at 60 days during rustication period. Different letters mean significantly different averages at $5 \%$. 


\section{DISCUSSÃO}

A taxa de sobrevivência de miniestacas é um indicador do sucesso do manejo empregado em casa de vegetação. A baixa sobrevivência está relacionada a vários fatores, como o estágio de lignificação das miniestacas, sobretudo de suas partes basais, ataques de fungos e manejo de água na casa de vegetação, qualidade fisiológica, entre outros. A perda de turgidez das miniestacas é decorrente de problemas no manejo e ambiente, e uma das consequências é a produção de ácido abscísico e de etileno que provocam queda de folhas precoce e interferem nos índices de enraizamento (GOULART; XAVIER, 2010).

Em materiais recalcitrantes como E. dunni, E. globulus e seus híbridos, normalmente mais sensíveis em sobreviver ao manejo adotado em sistemas de propagação vegetativa e menos responsivos ao enraizamento. A alta taxa de sobrevivência indica bom manejo ambiental da casa de vegetação para o enraizamento de miniestacas. Neste estudo, houve variações entre os clones na avaliação de sobrevivência. No clone de E. dunni, a taxa de sobrevivência foi de $89 \%$, sem diferenças significativas entre as arquiteturas de miniestacas. Bodrani et al. (2010) apontaram que elevada sobrevivência na casa de vegetação indicam adequado controle do ambiente. No mesmo trabalho, esse autor encontrou sobrevivência entre $87 \%$ e $98 \%$ em híbridos de $E$. benthamii x E. dunnii. Nos clones híbridos de $E$. urophylla x E. globulus maideinii e E. urophylla x E. globulus globulus, as taxas de sobrevivência foram de $60 \%$ e $66 \%$, respectivamente. O tratamento “árvore de natal” foi significativamente superior em relação à folha inteira (100\%) dos dois clones. A variação dos índices de sobrevivência é grande em trabalhos com híbridos de E. globulus. Borges et al. (2011) encontraram índices de 91\%, enquanto Paim et al. (2005) obtiveram índice de sobrevivência de $55 \%$. As diferenças nesses índices podem ser função de genótipos, principalmente nesses híbridos, em que uma das espécies parentais (E. globulus) é tida como recalcitrante ao enraizamento, como constatado também por Borges et al. (2011).

O índice de sobrevivência do clone de E. saligna na saída da casa de vegetação foi de 94\%, sem diferença significativa entre os tratamentos. Valores que podem ser confirmados em estudos realizados por Souza et al. (2013) e Santana et al. (2010), com variação no padrão e área foliar de miniestacas de clones tropicais (híbridos de E. urophylla x E. grandis).

$\mathrm{Na}$ avaliação de enraizamento, levou-se em consideração o número de estacas enraizadas em relação ao número de estacas vivas na saída da casa de vegetação. Dessa forma, foi possível verificar se o material genético é recalcitrante ao enraizamento ou o manejo empregado em minijardim clonal e casa de vegetação estão inadequados. A metodologia permite que clones em desenvolvimento, que poderiam ser descartados de programas comerciais das empresas devido aos baixos índices de aproveitamento final, possam vir a ser incluídos, caso o manejo adotado possa ser adequado às suas características e condições ambientais na casa de vegetação. Observação semelhante foi notada por Rosa et al. (2009), que, embora a sobrevivência das miniestacas na casa de vegetação não garanta sucesso no enraizamento delas, é fundamental para garantir o processo de propagação vegetativa como um todo. Ainda, Santana et al. (2010) apontaram que a sobrevivência de miniestacas é fundamental para a viabilidade econômica de viveiros. Dessa forma, as taxas de sobrevivência e, consequentemente, o aproveitamento final podem ser ampliados e os custos de produção, reduzidos.

No clone de E. dunnii, a taxa de enraizamento foi de $57 \%$, sem diferenças significativas entre as arquiteturas de miniestacas. Foi, portanto, o material genético menos responsivo ao enraizamento, indicando recalcitrância. Nos clones 37254 e 32864, a arquitetura de miniestaca “árvore de natal” apresentou resultado significativamente superior. Os índices de enraizamento foram de $81 \%$ e $86 \%$, respectivamente. Os tratamentos folha inteira e "árvore de natal" foram superiores no clone 37423, com 83\% de média. Índices similares foram encontrados por outros autores, em trabalhos com híbridos de E. globulus, E. dunnii e espécies de Eucalyptus tropicais (SOUZA JUNIOR; WENDLING, 2003; ALMEIDA, 2006; GOULART; XAVIER, 2010; BORGES et al., 2011).

Menos de 2\% das árvores-elite de Eucalyptus globulus selecionadas em programas de melhoramento apresentam enraizamento de miniestacas igual ou superior a 60\% (ALFENAS et al., 2004). Esses autores ainda relataram que a hibridação de Eucalyptus globulus com outras espécies de Eucalyptus, principalmente 
E. urophylla, pode aumentar a facilidade de propagação vegetativa, conforme observado neste estudo, em que os híbridos atingiram médias acima de $80 \%$. Borges et al. (2011) também obtiveram altos índices de enraizamento de híbridos de E. globulus. Schwanbach et al. (2008), em estudo com E. globulus utilizando método de cálculo de enraizamento com base no número de propágulos sobreviventes, encontraram índices de enraizamento de $93 \%$ e estão próximos aos obtidos neste estudo.

Existem poucos trabalhos publicados que relacionam a influência do padrão de miniestacas no seu enraizamento. Alguns reguladores de crescimento presentes nos tecidos da planta doadora de propágulos exercem influência na formação do enraizamento adventício. De acordo com Hartmann et al. (2002), para muitas espécies a presença de folhas ou parte delas é uma condição prévia, para produção de auxinas e cofatores de enraizamento que favorecem a rizogênese. Estudos recentes por Souza et al. (2013) e Santana et al. (2010) indicaram que a não redução da área foliar de miniestacas obtiveram os melhores resultados de enraizamento. Os resultados do estudo apontaram variações entre os clones. Santana et al. (2010) também obtiveram diferentes respostas para os clones estudados. Neste estudo, dois clones obtiveram melhores resultados de enraizamento com arquitetura "árvore de natal”, e para um clone o melhor resultado foi a arquitetura de folha inteira. Esses resultados evidenciam que a manutenção das folhas, em especial as folhas basais, privilegia e influencia a formação de raízes. Esse efeito positivo é, provavelmente, causado pela maior taxa fotossintética, pela manutenção das auxinas e pelo fato de as folhas basais estarem livres de sombreamento. Esses efeitos também foram observados por Santana et al. (2010).

O resultado do aproveitamento final é composto por vários efeitos, entre eles os principais: minijardim clonal, nutrição de minicepas, preparo de estacas, acondicionamento de estacas, tempo de transporte até a casa de vegetação, condições de manejo na casa de vegetação, irrigação, casa de sombra e rustificação. Como discutido anteriormente, esses efeitos em si podem não ser preponderantes no sucesso do enraizamento, mas no final o somatório desses pequenos efeitos pode aumentar, ou reduzir, o resultado geral do ciclo produtivo de mudas clonais. Dentro do ciclo, manter a sobrevivência das miniestacas é um dos principais fatores que influenciam o aproveitamento final, também apontado por Santana et al. (2010). Os resultados deste estudo confirmam que a baixa sobrevivência influencia o aproveitamento final. Em todos os outros clones, o tratamento "árvore de natal” foi superior apenas no clone 37254, o tratamento folha cortada não foi significativamente diferente, e no clone D. 1005 não houve diferenças entre os tratamentos. Ainda, ao se observarem as avaliações do clone 37254, os tratamentos folha cortada e folha inteira possuem o mesmo percentual de enraizamento, enquanto o aproveitamento final é $20 \%$ menor com folha inteira. Essa perda no final do ciclo foi influenciada pela baixa taxa de sobrevivência com esse tratamento, abaixo dos 50\%.

Os resultados deste trabalho são indicativos de que é necessário valorizar a arquitetura foliar das miniestacas, com possíveis incrementos nos índices de produção de mudas e ganhos nos custos de produção, uma vez que miniestacas “árvore de natal” e folha inteira utilizam menos cortes na sua confecção, se comparadas com miniestacas com folha cortada (50\%). Inclusive, Xavier et al. (2009) confirmaram que a arquitetura de miniestaca mais utilizada em viveiros florestais no Brasil é a folha cortada em 50\%. Ainda, segundo Simões et al. (2010), dentro do ciclo produtivo de mudas a etapa de coleta e plantio de miniestacas concentram $60 \%$ dos recursos financeiros necessários para produzir as mudas clonais.

Arquiteturas de miniestacas em folha inteira, “árvore de natal" e folha cortada resultaram em rendimentos operacionais, respectivamente de 600, 480 e 368 miniestacas, confeccionadas por hora de trabalho. Seria possível obter ganhos em rendimentos operacionais na ordem de $63 \%$, quando se utiliza arquitetura de folha inteira e 30\% com arquitetura "árvore de natal”, quando ambas são comparadas com a arquitetura-padrão, adotada pela empresa de folha cortada em 50\%. Em estudo semelhante, Souza et al. (2013) apontaram ganhos em rendimentos na produção de miniestacas na ordem de $23 \%$, trocando o padrão $50 \%$ folha cortada para a arquitetura de folha inteira.

Maiores produtividades proporcionam menor uso de mão de obra no viveiro ou, ainda, aumentam o número de mudas produzidas com o mesmo número de colaboradores. Em regiões do Brasil, onde a disponibilidade de mão de obra é considerada um gargalo

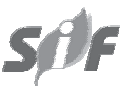

Revista Árvore, Viçosa-MG, v.38, n.5, p.819-827, 2014 
em diversos processos produtivos, a importância do uso de miniestacas com folha inteira tem a sua importância ampliada.

Este estudo evidenciou que, sempre que as taxas de aproveitamento final forem iguais, se deve optar por ordem de preferência pela arquitetura de folha inteira, “árvore de natal” e, por último, folha cortada em 50\%, em razão dos ganhos em produção.

\section{CONCLUSÕES}

A arquitetura de miniestacas influencia a sobrevivência, enraizamento e aproveitamento final da produção de mudas, exceto no clone de E. dunnii.

Os melhores resultados das características avaliadas foram obtidos com a arquitetura “árvore de natal” e folha inteira.

As arquiteturas folha inteira, “árvore de natal” e folha cortada em 50\% devem ser adotadas, preferencialmente nessa ordem, quando clones apresentam os mesmos resultados das características avaliadas, em razão dos ganhos operacionais.

\section{AGRADECIMENTOS}

À empresa CMPC Celulose Riograndense, pela disponibilização da estrutura do viveiro, incluindo o apoio da equipe técnica, e pela concessão de bolsa.

\section{REFERÊNCIAS}

ALFENAS, A. C. et al. Clonagem e doenças do eucalipto. 2.ed. Viçosa, MG: Universidade Federal de Viçosa, 2009. 500p.

ALFEnAS, A. C. et al. Clonagem e doenças do eucalipto. Viçosa, MG: Universidade Federal de Viçosa, 2004. 442p.

ALMEIDA, F. D. Propagação vegetativa de Eucalyptus cloeziana F. Muell. Por estaquia e miniestaquia. 2006. $74 \mathrm{f}$. Dissertação (Mestrado em Ciência Florestal) Universidade Federal de Viçosa, Viçosa, MG, 2006.

ASSIS, T. F.; MAFIA, R. G. Hibridação e clonagem. In: BORÉM, A. (Ed.). Biotecnologia florestal. Visconde do Rio Branco, MG: Suprema, 2007. p. 93-121.
ASSIS, T. F. Evolution of technology for cloning Eucalyptus in large scale. In: IUFRO INTERNATIONAL SYMPOSIUM, 2001, Valdivia, Chile. Colombo: EMBRAPA. Centro Nacional de Pesquisas Florestais, 2001. 4v.

BANZATTO, A. D.; KRONKA, S. N. Experimentação agrícola. Jaboticabal: FUNEP, 1989. 249p.

BORGES, S. R. et al. Enraizamento de miniestacas de clones híbridos de Eucalyptus globulus. Revista Árvore, v. 35, n. 3, p.425-434, 2011.

BRONDANI, G. E. et al. Miniestaquia de Eucalyptus benthamii $\times$ Eucalyptus dunnii: ( II ) sobrevivência e enraizamento de miniestacas em função das coletas e estações do ano. Ciência Florestal, v.20, n.3, p.453-465, 2010.

BRONDANI, G. E. Miniestaquia e micropropagação de Eucalyptus benthamii Maiden \& Cambage $x$ Eucalyptus dunnii Maiden. 2008. 118f. Dissertação (Mestrado em Engenharia Florestal) - Universidade Federal do Paraná, Curitiba, 2008.

GOULART, P. B.; XAVIER, A. Influência do modo de acondicionamento de miniestacas no enraizamento de clones de Eucalyptus grandis $\mathrm{x}$ E. urophylla. Revista Árvore, v.34, n.3, p.407-415, 2010.

GOULART, P. B. Influência do acondicionamento, antioxidantes, auxinas e seus cofatores no enraizamento de miniestacas de clones de Eucalyptus grandis x E. urophylla. 2007. 115f. Dissertação (Mestrado em Ciência Florestal) Universidade Federal de Viçosa, Viçosa, MG, 2007.

HARTMANN, H. T. et al. Plant propagation: principles and practices. 7.ed. New Jersey: Prentice-Hall, 2002. 880p.

HARTMANN, H. T. et al. Plant propagation - principals and practices. New Jersey: Prentice - Hall International, 1997. 770p.

NORBERTO, P. M. et al. Efeito da época de estaquia e do AIB no enraizamento de estacas de figueira (Ficuscarica L.). Ciência e

Agrotecnologia, v.25, n.3, p.533-541, 2001. 
PAIM, D. C. Physiological characterization of adventitious rooting in Eucalyptus globulus $\mathrm{x}$ maidenii mini-cuttings. In: CONGRESSO

BRASILEIRO DE FISIOLOGIA VEGETAL, 10.; CONGRESSO LATINO AMERICANO DE

FISIOLOGIA VEGETAL, 12., 2005, Recife. Anais... Recife: 2005. CD ROOM.

ROSA, L. S. et al. Efeito da dose de nitrogênio e de formulações de substratos na miniestaquia de Eucalyptus dunnii maiden. Revista Árvore, v. 33, n. 6, p. 1025-1035, 2009.

SANTANA, R. C. et al. Influence of leaf area reduction on clonal production of eucalyptus seedlings. Cerne, v.16, p.251-257, 2010.

SCHWAMBACH, J. et al. Adventitious rooting of Eucalyptus globulus x maidennii mini-cuttings derived from mini-stumps grown in sand bed and intermittent flooding trays: a comparative study. New Forests, v.36, n.3, p.261-271, 2008.

SIMÕES, D.; SILVA, M. R. Análise técnica e econômica das etapas de produção de mudas de eucalipto. Cerne, v.16, p.359-366, 2010.

SOUZA JUNIOR, L.; WENDLING, I. Propagação vegetativa de Eucalyptus dunnii via miniestaquia de material juvenil. Boletim de Pesquisa Florestal, n.46, p.21-30, 2003.

SOUZA, C. C. et al. Padrões de miniestacas e sazonalidade na produção de mudas clonais de Eucalyptus grandis Hill X E. urophylla S. T. Black. Revista Árvore, v.37, n.1, p.67-77, 2013.

XAVIER, A.; DA SILVA, R. L. Evolução da silvicultura clonal de Eucalyptus no Brasil. Agronomia Costarricense, v.34, n.1, jun., 2010. Disponível em: <http://www.scielo.sa.cr/ scielo.php?script=sci_arttext\&pid=S037794242010000100009\&lng $=$ es\&nrm $=$ iso $>$. acessado em 15 dez. 2013.

XAVIER, A.; WENDLING, I.; SILVA, R. L. Silvicultura clonal: princípios e técnicas. Viçosa, MG: Universidade Federal de Viçosa, 2009. 272p.

WENDLING, I. et al. Propagação clonal de híbridos de Eucalyptus spp. por miniestaquia. Revista Árvore, v.24, n.2, p.181-186, 2000.

WENDLING, I.; XAVIER, A. Influência do ácido indolbutírico e da miniestaquia seriada no enraizamento e vigor de miniestacas de clones de Eucalyptus grandis. Revista Árvore, v.29, n.6, p.921-930, 2005. 